\title{
Heparin-binding protein in lower airway samples as a biomarker for pneumonia
}

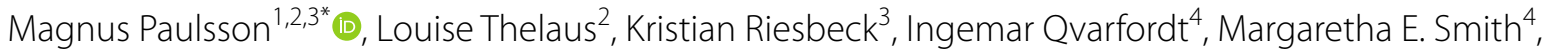 \\ Anders Lindén ${ }^{5,6}$ and Adam Linder ${ }^{1,2}$
}

\begin{abstract}
Objectives: Ventilator-associated pneumonia (VAP) is difficult to diagnose using clinical criteria and no biomarkers have yet been proved to be sufficiently accurate. The use of the neutrophil-derived Heparin-binding protein (HBP) as a biomarker for pneumonia was investigated in this exploratory case-control study in two intensive care units at a tertiary referral hospital.
\end{abstract}

Methods: Patients with clinical signs of pneumonia were recruited and bronchoalveolar lavage fluid (BALF) or bronchial wash (BW) samples were collected. Mechanically ventilated and lung healthy subjects were recruited as controls. HBP was measured with enzyme-linked immunosorbent assay.

Results: BALF was collected from 14 patients with pneumonia and 14 healthy controls. Median HBP in BALF pneumonia samples was $14,690 \mathrm{ng} / \mathrm{ml}$ and controls $16.2 \mathrm{ng} / \mathrm{ml}(p<0.0001)$. BW was collected from 10 pneumonia patients and 10 mechanically ventilated controls. Median HBP in BW pneumonia was $9002 \mathrm{ng} / \mathrm{ml}$ and controls $7.6 \mathrm{ng} / \mathrm{ml}$ $(p<0.0001)$.

Conclusions: These data indicate that HBP concentrations is significantly higher in lower airway samples from patients with pneumonia than control subjects and is a potentially useful biomarker for diagnosis of VAP.

Keywords: Pneumonia, Critical Care, Neutrophil Biology, Assisted Ventilation, Biomarkers, Bronchoalveolar lavage

\section{Introduction}

Ventilator-associated pneumonia (VAP), hospitalacquired pneumonia (HAP) and community-acquired pneumonia are conditions diagnosed based on clinical criteria and cultures from lower airway samples (LAS) [1]. The addition of biomarkers in plasma or bronchoalveolar lavage fluid (BALF) have not yet been proved to add substantial clinical value and poor biomarkers increase the risk of incorrect diagnosis, leading to unnecessary antibiotic treatment or increased time to correct diagnosis. The ATS/IDSA do not recommend biomarker-guided HAP/VAP diagnosis as the sensitivity and specificity in

\footnotetext{
*Correspondence: magnus.paulsson@med.lu.se

1 Department of Infectious Diseases, Skåne University Hospital, Lund, Sweden

Full list of author information is available at the end of the article
}

published reports failed to exceed 90\% [1]. Still, semiquantitative cultures on respiratory samples constitute gold-standard but these cultures are time consuming and can be biased by previous antibiotic treatment or presence of unculturable pathogens. Since VAP significantly increases mortality, a biomarker that accurately identifies VAP would be highly valuable [2].

Heparin-binding protein (HBP) is present in azurophilic granules and secretory vesicles of neutrophils and is released by activated neutrophils. Its known properties include antimicrobial effects, monocyte and macrophage activation, and particularly induction of vascular leakage [3]. Several studies have successfully evaluated plasma HBP as a biomarker for prognosticating organ dysfunction in sepsis and septic shock and there is evidence that HBP in BALF from patients with lung allografts can detect pulmonary infection with a cut-off value 
of $150 \mathrm{ng} / \mathrm{mL}$ [4]. In addition, the severity of bronchiectasis as well as exacerbations of cystic fibrosis correlate with sputum HBP $[5,6]$. In this exploratory study, we evaluated the biomarker potential of HBP in LAS from patients with pneumonia.

\section{Materials and methods}

Patients displaying clinical symptoms of pneumonia (temperature $>38{ }^{\circ} \mathrm{C}$ or $<36{ }^{\circ} \mathrm{C}$, purulent tracheal aspirate or decreased oxygen saturation) and radiological signs (new infiltrate on Chest X-ray) were recruited at the Departments of Infectious Diseases or Anesthesiology and Intensive Care at Skåne University Hospital (Malmö, Sweden) from 2015 to 2017. BALF $(3 \times 50 \mathrm{ml}$ sterile phosphate-buffered saline, PBS) was collected from the first 14 recruited patients ("Pneumonia 2016"), while BW $(2 \times 10 \mathrm{ml}$ PBS $)$ was collected from the following 10 patients ("Pneumonia 2017"). In both patient groups, the most affected lung segment was identified based on appearance at the time of bronchoscopy and chosen for sampling, as described [7]. Mechanically ventilated and endotracheally intubated control subjects for BW ( $n=10$, "BW control") were recruited to avoid the potentially confounding influence of mechanical ventilation on HBP concentrations. These control subjects were orthopedic patients without pulmonary disorders being planned for back surgery. To establish appropriate control samples for BALF, we utilized samples from unexposed healthy volunteers $(n=14)$, who were recruited to the Section of Respiratory Medicine, Sahlgrenska University Hospital (Gothenburg, Sweden) for a previously published study on the local effects of endotoxin exposure [8]. Baseline data of all included study subjects are summarized in Table 1.

We quantified HBP in BALF or bronchial wash (BW) from patients with pneumonia $(n=24)$ and from control subjects $(n=24)$ using a commercial ELISA kit

Table 1 Baseline characteristics of all included subjects

\begin{tabular}{|c|c|c|c|c|}
\hline \multirow[t]{2}{*}{ Variable } & \multicolumn{4}{|l|}{ Study group } \\
\hline & BALF “Pneumonia 2016” & BALF control & BW “Pneumonia 2017” & BW control \\
\hline Number of subjects & 14 & 14 & 10 & 10 \\
\hline Males & $8(57.1)$ & $7(50.0)$ & $8(80.0)$ & $4(40.0)$ \\
\hline Age (years) & $74(60.8-82.0)$ & $23.5(22-24)$ & $66(58.5-68.8)$ & $55(39-59)$ \\
\hline Current smoker & $0(0.0)$ & $0(0.0)$ & $2(20.0)$ & $0(0.0)$ \\
\hline COPD & $4(28.6)$ & $0(0.0)$ & $3(30.0)$ & $0(0.0)$ \\
\hline Other pulmonary diseases & $1(7.1)$ & $0(0.0)$ & $0(0.0)$ & $0(0.0)$ \\
\hline Diabetes mellitus & $4(28.6)$ & $0(0.0)$ & $1(10.0)$ & $1(10.0)$ \\
\hline Cardiovascular disease & $5(35.7)$ & $0(0.0)$ & $3(30.0)$ & $2(20.0)$ \\
\hline Non-pulmonary malignancy & $5(35.7)$ & $0(0.0)$ & $2(20.0)$ & $0(0.0)$ \\
\hline Radiographic lung infiltrate & $11(78.6)$ & NA & $6(60.0)$ & $0(0.0)$ \\
\hline Purulent sputum & $8(57.1)$ & $0(0.0)$ & $3(30.0)$ & $0(0.0)$ \\
\hline Temp $>38^{\circ} \mathrm{C}$ within the last $24 \mathrm{~h}$ & $12(85.7)$ & $0(0.0)$ & $6(60.0)$ & $0(0.0)$ \\
\hline Days with ventilator & $5(4.0-6.0)$ & NA & $2.5(1.8-6.5)$ & $0.5(0-1.0)$ \\
\hline Arterial oxygen saturation (\%) & $93.5(92.0-94.0)$ & $98(98.0-99.0)$ & $95.5(93.3-98.0)$ & $97(96-98)$ \\
\hline Plasma CRP (mg/l) & $69.5(23.5-142.8)$ & NA & $89.5(53.3-188.0)$ & $3.1(1.3-10.9)$ \\
\hline Blood leukocytes (10^9 cells/l) & $10.6(9.0-15.0)$ & $6.4(5.4-7.8)$ & $10.3(7.4-16.7)$ & $6.9(5.7-8.7)$ \\
\hline Blood neutrophils (10^9 cells/l) & $9.1(8.7-13.2)$ & $3.5(2.7-4.0)$ & $5.7(5.6-9.9)$ & $3.4(3.3-5.8)$ \\
\hline Gram-positive PPM & $5(35.7)$ & $\mathrm{NA}$ & $3(30.0)$ & $0(0.0)$ \\
\hline Gram-negative PPM & $7(50.0)$ & NA & $6(60.0)$ & $0(0.0)$ \\
\hline Viral PMM & $1(7.1)$ & NA & $0(0.0)$ & $0(0.0)$ \\
\hline Fungal PMM & $1(7.1)$ & NA & $0(0.0)$ & $0(0.0)$ \\
\hline Antibiotic treatment & $14(100.0)$ & $0(0.0)$ & $10(100.0)$ & $6(60.0)$ \\
\hline $\begin{array}{l}\text { Systemic steroid treatment }(=>10 \mathrm{mg} \\
\text { prednisolon) }\end{array}$ & $3(21.4)$ & $0(0.0)$ & $2(20.0)$ & $0(0.0)$ \\
\hline Inhalation steroid treatment & $3(21.4)$ & $0(0.0)$ & $6(60.0)$ & $0(0.0)$ \\
\hline Other immunosuppression & $1(7.1)$ & $0(0.0)$ & $1(10.0)$ & $0(0.0)$ \\
\hline
\end{tabular}

Data are presented as median (interquartile range) or $n(\%)$, unless otherwise stated. BW bronchial wash, BALF bronchoalveolar lavage fluid, COPD chronic obstructive pulmonary disease, CRP C-reactive protein, PPM potentially pathogenic microorganism; 
(Axis-Shield Diagnostics, Dundee, United Kingdom) in accordance to the manufacturer's instructions.

Statistical analysis was made using Prism software (Graphpad v8.4.3, San Diego, CA). Two-tailed $p$-values were calculated using Mann-Whitney's test. A receiveroperating characteristic (ROC) curve was calculated with $95 \%$ confidence interval $(\mathrm{CI})$.

\section{Results}

The concentration of HBP was significantly increased in samples from patients with pneumonia compared those from control subjects, whether collected as BALF or as BW (Fig. 1). Two "Pneumonia 2017" subjects were excluded from further analysis because of negative cultures, all other samples contained bacterial pathogens. All control subjects had HBP concentrations below the previously proposed cut-off of $150 \mathrm{ng} / \mathrm{ml}$ and all pneumonia patients displayed concentrations above $150 \mathrm{ng} /$ $\mathrm{ml}$. The two excluded subjects both had HBP values below $150 \mathrm{ng} / \mathrm{ml}$. We observed no statistically significant difference in HBP concentrations between BALF and BW samples. Given this, a ROC curve was calculated using pooled samples from both pneumonia patients and control subjects. Best diagnostic accuracy was achieved using a cut-off of $206 \mathrm{ng} / \mathrm{ml}$, that yielded a sensitivity to detect pneumonia of $100 \%(95 \% \mathrm{CI}=85.1-100 \%)$ and a specificity of $100 \%(95 \% \mathrm{CI}=86.2-100 \%)$.

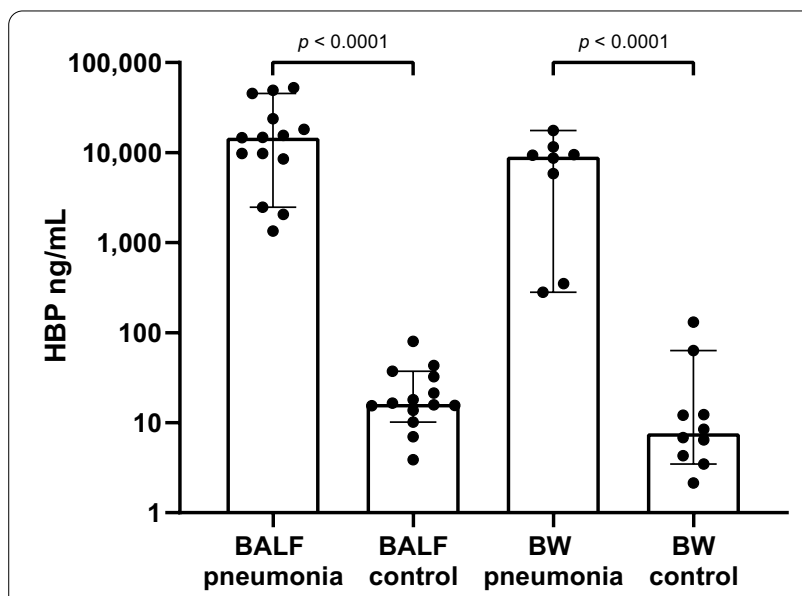

Fig. 1 Concentrations of Heparin-binding protein (HBP) were measured in bronchoalveolar lavage fluid (BALF) and bronchial wash (BW) samples from patients with pneumonia and from healthy control subjects. The median HBP in BALF "Pneumonia 2016" samples was $14,690 \mathrm{ng} / \mathrm{ml}$ and BALF control $16.2 \mathrm{ng} / \mathrm{ml}(p<0.0001)$. The median HBP in BW"Pneumonia 2017" samples was 9,002 ng/ml and BW control median was $7.6 \mathrm{ng} / \mathrm{ml}(p<0.0001)$. Bar graph show median values and $95 \%$ confidence intervals. Each dot represents one study subject. Statistical evaluations were made with MannWhitney test. $P$-values are indicated on the graph

\section{Discussion}

The usefulness of HBP as biomarker for pneumonia depends on its accuracy in differentiating pneumonia from other diagnoses, ease of sample collection and time from sampling to results. Importantly, HBP can be analyzed using a point-of-care device in less than $30 \mathrm{~min}$, a fact that enables HBP in LAS to influence the decision to start antibiotic therapy. The recent VAPrapid2 trial investigated if IL-1 $\beta$ and IL-8 in BALF were useful in an antibiotic stewardship design [9]. However, antibiotic prescription remained unchanged, which was partly attributed to reluctance for collecting BALF in critically ill patients. In view of this, we included a BW cohort and found no significant difference in HBP concentrations between BALF and BW. Although not as accessible as blood samples, BW samples are specific for the conditions in the lungs and the smaller lavage volumes of BW are less likely to cause adverse effects than BAL and may be more tolerable for the clinician. In addition, the BW control group was mechanically ventilated and better matched to the pneumonia patients in terms of age. Yet, the HBP values in the BW control group were similar to those in the BALF control group and indicated no increase in HBP related to mechanical ventilation.

We did not normalize HBP concentrations to urea or return volume, because normalization may confound the results and omitting normalization is in line with current recommendations and imitates the clinical setting [10]. Instead, our sampling protocol was standardized with BALF collected using $3 \times 50 \mathrm{ml}$ lavage fluid and BW collected with $2 \times 10 \mathrm{ml}$. Yet, we obtained very clear-cut results. The latter and the fact that we explored a limited study sample, supports the idea that HBP possesses substantial potential as a robust biomarker for clinical use. Nevertheless, a larger study sample would allow independent ROC analysis of each material, so larger and prospective cohort studies in critically ill patients are warranted in the near future to verify the diagnostic accuracy and the optimal positive test cut-off.

\section{Conclusions}

In conclusion, this exploratory study forward evidence that the median HBP concentration in LAS is enhanced around a 1000-fold in patients with pneumonia. This indicates that HBP in LAS is a potential biomarker that may be added to current diagnostic tools for VAP.

\section{Abbreviations}

BALF: Bronchoalveolar lavage fluid; BW: Bronchial wash; COPD: Chronic obstructive pulmonary disease; CRP: C-reactive protein; HAP: Hospitalacquired pneumonia; HBP: Heparin-binding protein; LAS: Lower airway samples; PBS: Phosphate-buffered saline; PPM: Potentially pathogenic 
microorganism; ROC: Receiver-operating characteristic; VAP: Ventilator-associated pneumonia.

\section{Acknowledgements}

We thank Jane Fisher for language editing.

\section{Authors' contributions}

MP, AnL and AdL conceived and designed the work. MP, IQ, MS, KR and AnL provided samples. MP and LT analyzed the samples and MP drafted the work. All authors were involved in data interpretation, revised the manuscript for important intellectual content, approved of the version to be published and agree to be accountable for all aspects of the work. All authors read and approved the final manuscript.

\section{Funding}

This work was supported by the Swedish Heart Lung Foundation (K.R.: \#20180401, An.L. \#20180315), Swedish Research Council (M.P. \#2018-06924, An.L. \#2016-01563, K.R. \#2019-01053), Anna and Edwin Berger foundation (K.R.), Skåne County Council's research and development foundation (K.R.), Swedish Society for Medical Research (M.P., Ad.L.), the Crafoord foundation (Ad.L.), the foundation of Alfred Österlund (Ad.L.) and the Royal Physiographical Society (M.P.). All above mentioned financial activities are outside of the submitted work and no sponsor exerted any influence on the study protocol, the data interpretation or the contents of the manuscript.

\section{Availability of data and materials}

The datasets used and/or analysed during the current study are available from the corresponding author on reasonable request.

\section{Declarations}

Ethics approval and consent to participate

All parts of this study have been reviewed and approved by the Regional Ethical Review Boards in Gothenburg (Dnr S618-02; T065-04; T683-07) or Lund (Dnr 2014/529; 2016/523) and conforms to the guidelines by the World Medical Association (the Declaration of Helsinki).

\section{Consent for publication}

Not applicable.

\section{Competing interests}

M.P. reports personal fees from MSD for participation in expert input forums, outside the submitted work; All other authors report nothing to disclose.

\section{Author details}

'Department of Infectious Diseases, Skåne University Hospital, Lund, Sweden. ${ }^{2}$ Division of Infection Medicine, Department of Clinical Sciences, Faculty of Medicine, Lund University, BMC B14, SE221 85 Lund, Sweden. ${ }^{3}$ Clinical Microbiology, Department of Translational Medicine, Faculty of Medicine, Lund University, Malmö, Sweden. ${ }^{4}$ Department of Internal Medicine and Clinical Nutrition, Institute of Medicine, Sahlgrenska Academy, University of Gothenburg, Gothenburg, Sweden. ${ }^{5}$ Unit for Lung and Airway Research, Institute of Environmental Medicine, Karolinska Institutet, Stockholm, Sweden. ${ }^{6}$ Karolinska Severe COPD Center, Department of Respiratory Medicine and Allergy, Karolinska University Hospital, Stockholm, Sweden.

Received: 16 February 2021 Accepted: 27 May 2021

Published online: 08 June 2021

\section{References}

1. Kalil AC, Metersky ML, Klompas M, Muscedere J, Sweeney DA, Palmer $L B$, et al. Management of adults with hospital-acquired and ventilatorassociated pneumonia: 2016 clinical practice guidelines by the Infectious Diseases Society of America and the American Thoracic Society. Clin Infect Dis. 2016;63:e61-111.

2. Ferrer M, Torres A. Epidemiology of ICU-acquired pneumonia. Curr Opin Crit Care. 2018:24:325-31.

3. Linder A, Soehnlein O, Åkesson P. Roles of heparin-binding protein in bacterial infections. J Innate Immun. 2010;2:431-8.

4. Aspelund AS, Hammarström H, Inghammar M, Larsson $H$, Hansson L, Christensson B, et al. Heparin-binding protein, lysozyme, and inflammatory cytokines in bronchoalveolar lavage fluid as diagnostic tools for pulmonary infection in lung transplanted patients. Am J Transplant Off J Am Soc Transplant Am Soc Transplant Surg. 2018;18:444-52.

5. Smith A, Lang J, Keir HR, Finch S, Aliberti S, Sibila O, et al. Heparin Binding Protein in sputum compromises epithelial defence and relates to bronchiectasis severity. Eur Respirat J. 2019;54:PA2172.

6. Hovold G, Palmcrantz V, Kahn F, Egesten A, Påhlman LI. Heparin-binding protein in sputum as a marker of pulmonary inflammation, lung function, and bacterial load in children with cystic fibrosis. BMC Pulm Med. 2018;18:1-8.

7. Paulsson M, Che KF, Ahl J, Tham J, Sandblad L, Smith ME, et al. Bacterial outer membrane vesicles induce vitronectin release into the bronchoalveolar space conferring protection from complement-mediated killing. Front Microbiol. 2018:9:1559.

8. Glader P, Smith ME, Malmhall C, Balder B, Sjostrand M, Qvarfordt I, et al. Interleukin-17-producing T-helper cells and related cytokines in human airways exposed to endotoxin. Eur Res J. 2010;36:1155-64.

9. Hellyer TP, McAuley DF, Walsh TS, Anderson N, Morris AC, Singh S, et al. Biomarker-guided antibiotic stewardship in suspected ventilator-associated pneumonia (VAPrapid2): a randomised controlled trial and process evaluation. Lancet Respir Med. 2020;8:182-91.

10. Martinu T, Koutsokera A, Benden C, Cantu E, Chambers D, Cypel M, et al International Society for Heart and Lung Transplantation consensus statement for the standardization of bronchoalveolar lavage in lung transplantation. J Heart Lung Transplant. 2020;39(11):1171-90.

\section{Publisher's Note}

Springer Nature remains neutral with regard to jurisdictional claims in published maps and institutional affiliations.

Ready to submit your research? Choose BMC and benefit from:

- fast, convenient online submission

- thorough peer review by experienced researchers in your field

- rapid publication on acceptance

- support for research data, including large and complex data types

- gold Open Access which fosters wider collaboration and increased citations

- maximum visibility for your research: over $100 \mathrm{M}$ website views per year

At BMC, research is always in progress.

Learn more biomedcentral.com/submissions 